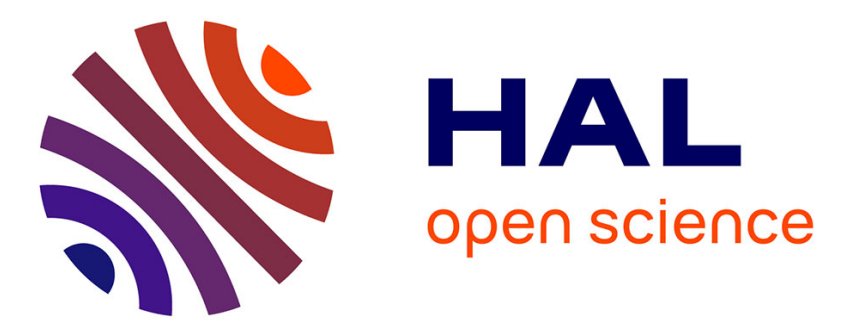

\title{
Sports Training System for Situational Judgment Improvement by Reliving First Person Viewpoint
}

\author{
Shunki Shimizu, Kaoru Sumi
}

\section{To cite this version:}

Shunki Shimizu, Kaoru Sumi. Sports Training System for Situational Judgment Improvement by Reliving First Person Viewpoint. 16th International Conference on Entertainment Computing (ICEC), Sep 2017, Tsukuba City, Japan. pp.189-195, 10.1007/978-3-319-66715-7_20 . hal-01771272

HAL Id: hal-01771272

https://hal.inria.fr/hal-01771272

Submitted on 19 Apr 2018

HAL is a multi-disciplinary open access archive for the deposit and dissemination of scientific research documents, whether they are published or not. The documents may come from teaching and research institutions in France or abroad, or from public or private research centers.
L'archive ouverte pluridisciplinaire HAL, est destinée au dépôt et à la diffusion de documents scientifiques de niveau recherche, publiés ou non, émanant des établissements d'enseignement et de recherche français ou étrangers, des laboratoires publics ou privés. 


\title{
Sports Training System for Situational Judgment Improvement by Reliving First Person Viewpoint
}

\author{
Shunki Shimizu ${ }^{1 *}$ and Kaoru Sumi ${ }^{1,2}$ \\ ${ }^{1}$ Future University Hakodate, Kameda 116-2 Hakodate, Japan \\ g2117025@fun.ac.jp \\ 2kaoru.sumi@acm.org
}

\begin{abstract}
Situational judgment in a ballgame is said to be more difficult to obtain than skills such as basic passing and shooting. However, by displaying the images seen by a player from a first person viewpoint, it is possible to have a user perform the actual sports action performed by the player and experience the same feeling. We developed a situational judgment training system for this purpose. In this research, we particularly aim to improve the user's situational judgment ability and focus on learning situations in ballgames in which the user does not know how to move to get the ball. The results of evaluation experiments conducted with six subjects indicate that the gameplay of users improved such that they were consciously able to move and get the ball better than they had before using the system.
\end{abstract}

Keywords: First Person Viewpoint, Situational Judgment, Reliving.

\section{Introduction}

It is said that judging the situation in ballgames is more important than basic skills like passing, shooting, and dribbling. One of the reasons why situational judgment skills is important is that the attacking sides' mistakes might instantly replace offense and defense because they play to directly force each other in goal-oriented ballgames, requiring instant situational judgment [1]. Another reason is spatial ability. It has been stated that one of the reasons is that players can find empty space or other players around whom there are no defenses when viewed from a third person viewpoint, but they lose empty space and the free player when they play in the court and watch from a first person viewpoint [1].

Various studies have been conducted on situational judgment and sports training. Further, we can experience a player's viewpoint through the use of Virtual Reality (VR) devices such as Head Mount Display (HMD). However, even though we can experience sports scenes from a player's viewpoint, the experience is not interactive as we cannot perform any action in the game or somewhat interact with the video.

Using JackIn [2], people's activities are shared and viewers can be assisted or guided by other people's expertise. It enables people to experience the viewpoint of professional players. With the first person viewpoint streaming from a person wearing 
a see-through HMD with a camera called JackIn Head, another person can share in the first person's viewpoint. Covaci et al. [3] developed a VR-based free throw training system that is highly reliable.

A system that provides experiences from a first person viewpoint is useful for effectively and quickly learning motions and exercises [4]. It is also easier to remember first person images than third person images [5]. Nakagawa stated that situational judgment involves applying the most appropriate play from experience and memory [6]; thus, reliving experiences from a first person viewpoint leads to improved situational judgment.

Our aim is to develop a sports training system that enables situational judgment and spatial awareness from a third person viewpoint and relive interaction from a first person viewpoint. We focus on situations in which players have difficulty getting the ball and how to move and judge the situation in such scenarios. From the background that spatial awareness is difficult, first we discuss how to move to get the ball from a third person viewpoint. Then, we analyze the experience from a first person viewpoint.

\section{Sports Training System for Situational Judgment by Reliving First Person Viewpoint}

The proposed system comprises two subsystems: a whiteboard system and a reliving system. The system is similar to a strategy board used in games such as basketball or soccer. In this system, users set the situations they wish to learn by moving pieces and 3D images corresponding to each piece's position are displayed.

In the reliving system, images corresponding to each piece's position are displayed in the whiteboard system. First, the system visually teaches the manner in which the movement is executed in the various situations in videos from a third person viewpoint. Then, the user is asked to experience a virtual basketball by performing the actual basketball action from a first person viewpoint. The system teaches only movement and judgment to get the ball because our focus is on learning in a situation where the user does not know how to move to get the ball.

The system was developed in C\# using Microsoft Visual Studio 2015 and the Unity development engine, developed by Unity Technology. In addition, Microsoft Kinect v2 for Windows is utilized. Kinect is a peripheral device that is able to sense body movements, gestures, and voice, and carry out face tracking, etc. We selected it to develop the interactive system owing to its many functions.

The system hardware comprises one Kinect, a projector, and fisheye lens in a dome made from cardboard, as depicted in Figure 1. We project a video in a part of the dome's side and magnify the projection range via the fisheye lens. The Kinect is situated between the user and the projector. The dome is approximately $180 \mathrm{~cm}$ high and sufficiently wide that the user can move two or three steps. We conducted experiments in a limited space so as to simulate a system that users can use in their house. 

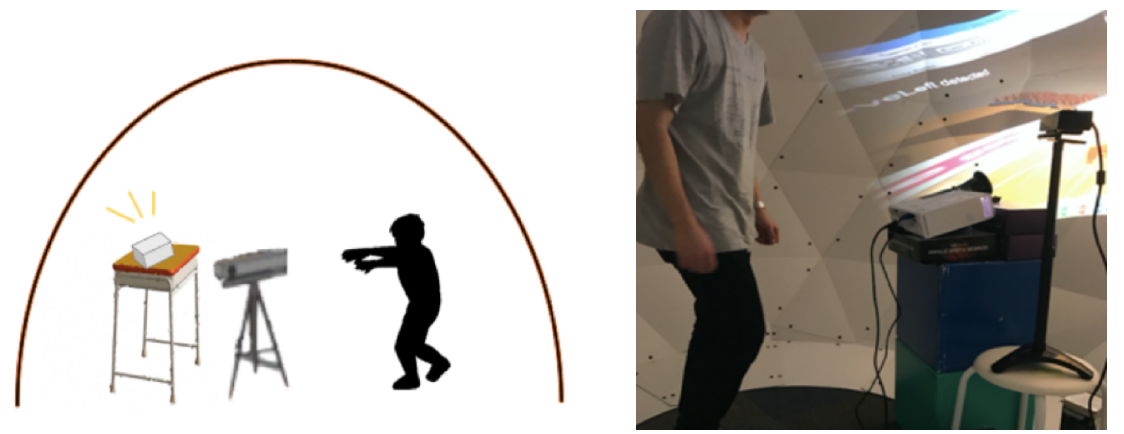

Fig. 1. Implementation environment: The inside and outside of the dome.

\subsection{Teaching from Third Person Viewpoint}

In this study, the system teaches how to move to get a ball without dribbling so as to reduce the difference in individual ability. At this point, the system provides support for the following three skills (for which we made videos based on sports lessons from professional basketball players in Hokkaido, Japan) ${ }^{1}$. 1) Cutting and Back cut, 2) Pass and Run, 3) High or low speed movement.

Cutting is a movement in which players attempt to get the ball by shaking the defense. Back cut refers to cutting behind the defense. Tips for back cut are when the defense cannot observe; otherwise, the movement is read by the defense. The system teaches users these kinds of movements.

Pass and Run is a series of movements in which passes are thrown to make good use of empty space based on moving when they throw a pass. In Pass and Run, the player who threw the pass must move. In doing, if they are unable to get the ball, the space where the player used to stand is empty such that other players move to get the ball. Users repeat these movements.

Users don't have to run at full speed at all times. It is because defense would make it easy for the defense to follow. In that case, it can be easy to get the ball via high or low speed movement. By doing so, it is easy to get the ball because of the distance between offence player and defense player.

This system teaches how to get the ball with their three basic skills. First the system explains cutting, pass and run, and movement by high or low speed moving. Next it gives examples of these movements from third person viewpoint. Subsequently, it teaches them from a first person viewpoint and the user tries to relive the experience. Figure 2 is example of the scene used to teach the skills from third person viewpoint.

1 NHK E Tele, Television Sports Classroom

"Let's learn basketball team style", 9/11, 2016

URL : https://www.levanga.com/news/11389.html 
An example of using back cut

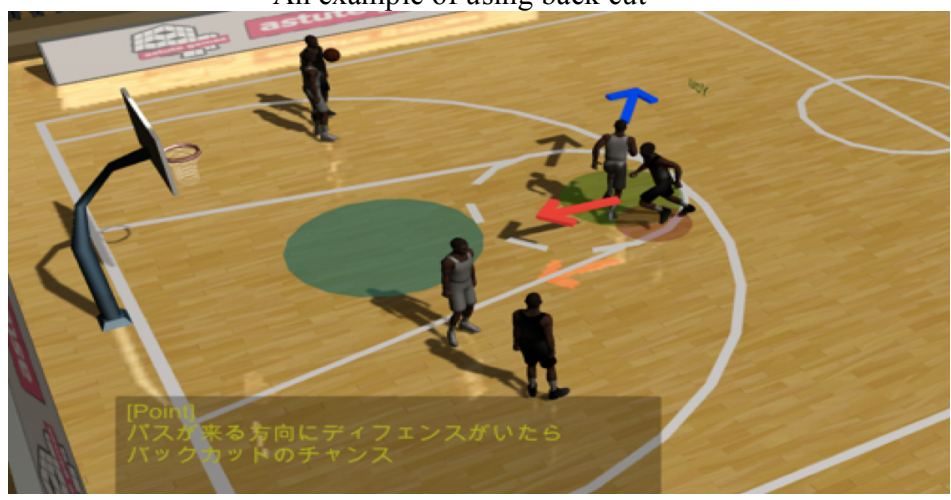

To be moved by high or low speed moving

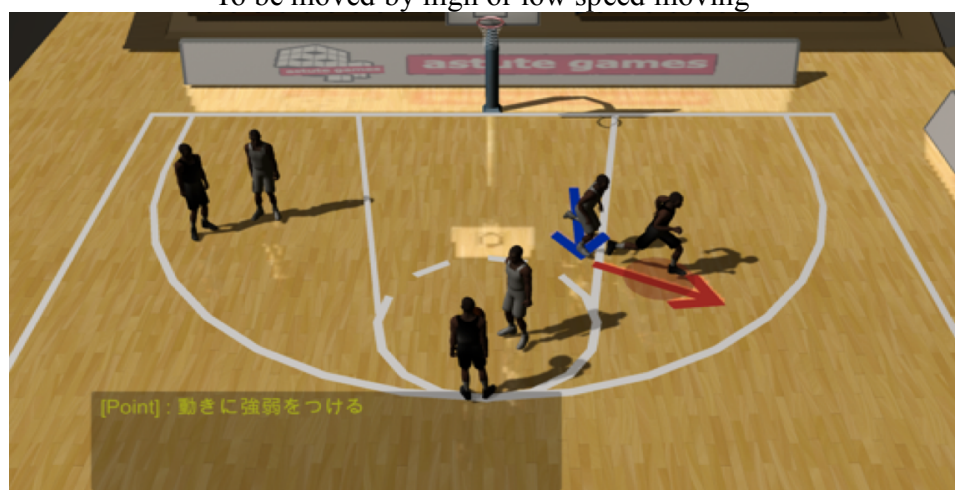

Fig. 2. Content of video from a third person viewpoint

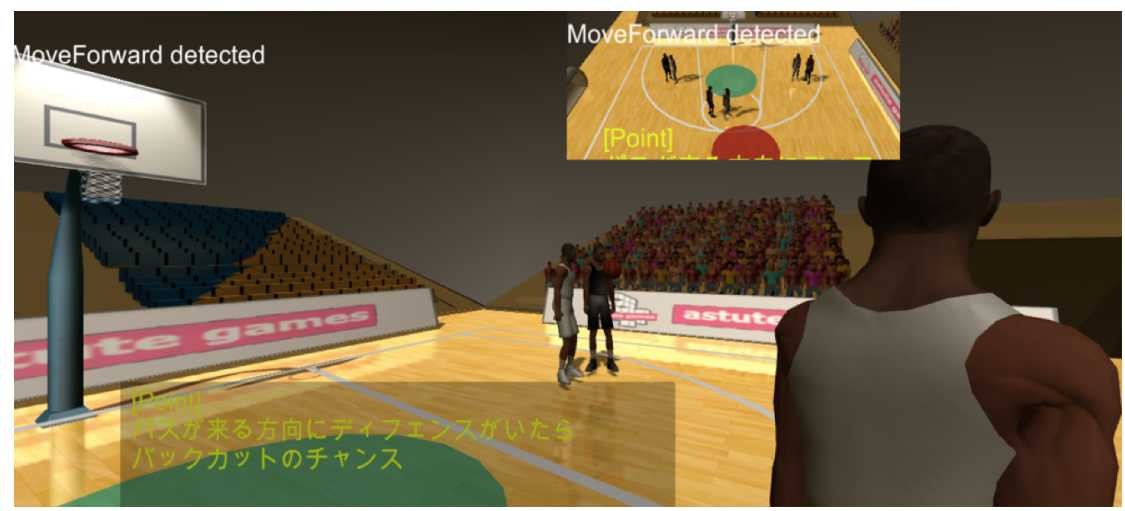

Fig. 3. Example of teaching content from a first person viewpoint 


\subsection{Reliving from First Person Viewpoint}

First person viewpoint lets users relive the experience of a player. All videos in first person viewpoint shift from third person viewpoint to the player's eyes. Users can move the player in the video by moving back and forth and around because Kinect senses the user's movements and gestures. They move following arrows on the screen and voice teaching in this system. Figure 3 is example of reliving from first person viewpoint.

\section{Experiment}

We experimentally verified whether situational judgment skill to get the ball improved after using the system. Six male university students (two groups of three students) participated in the experiment: group 1 for 3 days and the group 2 for 2 days to determine the relationship to days. We played short three-minute games two times with three subjects and three basketball experiences we had collected in the gym of the same university on the first and final days. In that time, we established the following set of rules. 1) Three on three in a half court, 2) Three subjects play only offense, 3) No dribbling.

After playing on the first day, we carried out a questionnaire survey before using the system. Then, each participant used the system in the cardboard dome. In this system, we first displayed explanatory videos about "Back cut" and "Pass and Run" and a scene to use three skills to get the ball from a third-person viewpoint two times each. Next, they relived the experience two times each time from the first person viewpoint. Finally, we played the short games at the same place on the final day.

\subsection{Experimental Results and Analysis}

We assessed the system based on Game Performance Assessment Instrument (GPAI), developed Griffin et al. [7] to determine its learning effect. GPAI was developed to measure game performance behaviors that demonstrate tactical understanding, as well as the player's ability to solve tactical problems by selecting and applying appropriate skills. In this study, we analyzed "support" based on GPAI. "support" are defined that provides appropriate support for a teammate with the ball (or projectile) by being in a position to receive a pass so "support" are important offthe-ball movement skills.

We recorded all games played before and after using the proposed system using a video camera. Then, we analyzed the video and assessed how well subjects executed "support" movements. We assessed whether or not player movement is a "support" movement as follows and counted each instance as one. 


\section{Discussion}

In group 1, the three subjects were consciously able to move to get the ball after using the system, but subjects $\mathrm{A}$ and $\mathrm{C}$ did not improve their situational judgment statistically. For subject B, we could always see his aggressiveness and his situational judgment improved by approximately $14 \%$ after using the system.

In group 2, there was growth little by little for each of the three subjects. Both subjects $\mathrm{D}$ and $\mathrm{F}$ improved by $10 \%$ or more compared to before system use, and subject $\mathrm{E}$ had a result of $50 \%$ or more before and after using system.

We conducted experiments for three days with group 1 and for two days with group 2, but group 2 produced better results. This is because subjects also involved factors such as differences in combinations and differences in sports ability. Two of the subjects had experience in soccer and handball, which are classified as games in which attack is directed toward the enemy's goal, like basketball. This resulted in similar movements and early recognition of sensation, and may have caused them to improve by $10 \%$ or more as a result. Subjects commented that "I've had similar practice during high school club activities," during the experiment. Therefore, although it seems to be individual differences, we believe that the improvement rate will change.

There were many instances where on-the-ball players missed to pass the ball. This system mainly supports the movement of off-the-ball players. Therefore, simulations in the case of a failure such as a pass mistake pattern were not conducted. However, if on-the-ball movement is supported, we believe that improvement of judgment can be expected for all subjects.

Also the participants said that most of them understood the contents that the system taught. However, there were many comments that the body does not move quickly when it comes to actual play. However, the subjects sufficiently understood the contents because they stated that they had the movement experience and that it is easy to understand the teaching content, which good points of this system. Therefore, we need to improve the system by judging how we can move the body instantaneously.

We cannot state definitively say that there is only a small improvement in judgment by using the system because the system is not yet perfect and this experiment was a short-term implementation. While evaluating this experiment, we focused only on the support movement in this research, and ignored the on-the-ball player. However, it is felt that if the players previously experienced sports in which they attack toward the enemy's goal, the improvement margin would increase.

\section{Conclusion}

In this study, we developed a sports training system that improves situational judgment by reliving the first person viewpoint. We focused on "judging to get the ball" and verified whether judgment improved after using the system. The experimental results obtained indicate that it is possible for players to further improve if they have prior experience with interstitial sports such as basketball or soccer. 


\section{References}

1. M. Fujiwara.: Practice about "how to use space" in the lesson of basketball. Research Journal of Sports Science in Nara Women's University, 15, pp. 80-81 (2013).

2. S. Kasahara., J. Rekimoto.: JackIn: Integration the First Person View with Out-of-Body Vision Generation for Human-Human Augmentation. IPSJ Journal vol.56 No.4, pp. 1-8. (2014).

3. Alexandra Covaci, Anne-Helene Olivier, Franck Multon, Visual Perspective and Feedback Guidance for VR Free-Throw Training, Virtual Reality Software and Technology, p7982, 2015

4. Ruby, P., Decety, J.: Effect of subjective perspective taking during simulation of action: a PET investigation of agency. NAT Neuroscience 4:546-550, 2001.

5. Ryan, ED., Simons, J.: Efficacy of mental imagery in enhancing mental rehearsal of motor skills: J Sport Psychology Vol.4, pp.41-51, 1982.

6. S. Nakagawa.: Some basic concepts for the study on situational judgment in ball games, Japanese Society of Physical Education Vol.28(4), pp. 287-289, 1984

7. Linda Griffin et al., T. Takahashi \& M. Okade (eds.): Teaching Sport Concepts and Skills, Jun.1999, pp. 100-102, Taishukan Press. 